\title{
Modeling and analyzing army air assault operations via simulation
}

\author{
Ihsan Sabuncuoglu' and Gökhan Virlan²
}

sim.sagepub.com

\begin{abstract}
It is very important to use combat simulation in personnel training and preparing them for different war scenarios. Simulation modeling and analysis methodologies gives an opportunity to staff officers and commanders to measure the effectiveness of their plans and take necessary precautions. In a simulated environment, different combat scenarios can be tried without actually deploying the units to the combat area and getting 'losts, costs, and risks'. As one of the most complicated and decisive operations on the road to victory, 'air assault operations' are high-risk, high-payoff operations that, when properly planned and vigorously executed, allow commanders to take the initiative in combat areas. In this study, we develop a simulation system called the Air Assault Operations Simulation Model (AAOSM) that allows planners to: (I) analyze air assault operations early in the decision process and refine those models as their decision process evolves, (2) perform 'bottleneck analysis' of the preplanned operations, and (3) perform 'risk management' of the operation before conducting the real operation. AAOSM is developed by using the ARENA simulation programming language. The outputs of the model are analyzed using statistical methods. The factors that have significant effect on air assault operations are identified. The possible scenarios are also evaluated for different weather and terrain conditions and for various refueling and maintenance configurations.
\end{abstract}

\section{Keywords}

air assault operations, simulation, military simulation

\section{Introduction}

Air assault is the military operation for the movement of military forces by using helicopter or aircraft assets to maneuver on the battlefield under the control of the ground or air commander to engage and destroy enemy forces or to seize and hold key terrain. The movement of soldiers, weapons, and material by army aviation units is not a simple task. It needs to be precisely planned and vigorously executed to allow friendly forces to strike over extended distances and terrain barriers to attack the enemy. In general, well planned air assault task forces can attack enemy positions from any direction, conduct deep attacks and raids beyond the forward line of own troops using helicopters, rapidly place forces at tactically decisive points in the battle area, bypass enemy positions, conduct operations under adverse weather conditions and can be used at night to facilitate deception and surprise.

There are also certain limitations on air assault operations. First of all, an air assault task force relies on continuous helicopter support throughout any air assault operation. The helicopters may be limited by adverse weather, extreme heat and cold, and other environmental conditions such as blowing snow and sand that limit flight operations or helicopter lifting capability. In addition to inherent randomness in the process, hostile aircraft, air defense, and electronic warfare action, the availability of suitable landing zones (LZs) and pickup zones (PZs), high fuel and ammunition consumption rates complicate the air assault operations. Thus, a good planning process and proper

\footnotetext{
'Department of Industrial Engineering, Bilkent University, 06800 Ankara, Turkey.

${ }^{2}$ Army Aviation School, 06790 Ankara, Turkey.

Corresponding author:

Professor Ihsan Sabuncuoglu, Chair, Department of Industrial Engineering, Bilkent University, 06800 Ankara, Turkey

Email: sabun@bilkent.edu.tr
} 
execution of the plan are keys to the success in air assault operations.

In this study, a simulation model for Turkish air assault operations is developed to: (1) analyze air assault operations early in the decision process and revise these models as the decision process evolves; (2) perform 'bottleneck analysis' of the preplanned operations; and (3) perform 'risk management' of the operation before conducting the real operations so that capabilities and limitations of military forces can be identified and necessary actions can be taken accordingly.

There are relatively few studies of air assault operations reported in the literature. This may be due to the fact that research in this area is not open to the public considering the classified nature of the topic. Published work is usually available in the form of training tools for commanders and analysis tools for the planners. Some of these examples are as follows.

Henry ${ }^{1}$ developed a simulation tool called Corps Battle Simulation, which is used as the US Army standard tool for training commanders and their staff. Blais $^{2}$ introduced the Marine Tactical Warfare Simulation (MTWS) system that includes basic design philosophy, exercise control concept, and combat modeling approach. Garrabbrants ${ }^{3}$ proposed 'an expansion of simulation systems role to support all levels of command and control functions, especially staff planning after receipt of orders and mission rehearsal'. This simulation is the next-generation training system for the US Marine Corps. It is designed to support training of tactical commanders and their staffs for various exercises.

The following studies are examples of the second line of research in which simulation is used as a decision tool for analyzing plans: Rubin and Sowers ${ }^{4}$ presented air operations modeling in a war-gaming environment. Litko and Carter $^{5}$ developed a simulation model to support the decisions for employment of aircrews in Operation ZAA Desert Storm. The authors developed the components of the airlift system and the rules for the desert storm scenarios. In another study, Zahn et al. ${ }^{6}$ conducted a joint study by the US Air Force to model the aerospace support equipment usage during the deployment process of fighter aircraft. Briggs et al. ${ }^{7}$ developed a hybrid analytical/simulation model to plan for mass tactical airborne operations. This automated tool enables the user to load aircraft according to the user specifications in the shortest possible of time.

There are studies in which air warfare is considered. For example, Fossett et al. ${ }^{8}$ developed an assessment procedure for simulation models for air defense systems. Popken and $\mathrm{Cox}^{9}$ proposed a simulation optimization approach to airfare planning. The authors demonstrated that such an integrated approach (a combination of simulation and linear programming) can successfully be used to generate, evaluate, and improve Blue plans while assuming that Red intelligently reallocates its forces. In another study, Taylor and Lane ${ }^{10}$ proposed a framework for the development of a novel family of military campaign simulation models. There are also some analytical studies in the literature. For example, Rosenthal and Walsh ${ }^{11}$ developed a mixed integer programming (MIP)-based mathematical model for an aircraft carrier in transit. Baker et al. ${ }^{12}$ proposed a time dynamic mathematical model of an airlift system for a large-scale military deployment process. Schumacher et al. ${ }^{13}$ developed a MIP formulation for the optimization of air vehicle operations. The reader can refer to Turner and Carstens ${ }^{14}$ for other technical issues (both hardware and software) of air assault operations.

To the best of the authors knowledge, this is the first study in the literature that analyzes the entire air assault operation via discrete simulation. Specifically, we model the system using ARENA and investigate the effects of the important factors with regards to these operations.

The rest of the paper is organized as follows. Section 2 describes the system under consideration and some important details. The proposed model called Air Assault Operations Simulation Model (AAOSM) is also developed in this section. Section 3 discusses the experimental setting and the numerical results. Section 4 presents the output data analysis that the comparison of alternative system designs. Section 5 gives the concluding remarks and further research directions.

\section{The system description and simulation model}

A successful air assault operation requires a well-prepared and detailed planning process in which the factors such as mission, enemy, terrain, troop's available-time (METT-T) should be carefully considered. Five basic plans are usually developed for each air assault operation. These are: ground tactical plan, landing plan, air movement plan, loading plan, and staging plan. All of these plans are somehow interrelated and should not be developed independently.

Figure 1 describes the basic stages of the air assault operations schematically. The ground tactical plan is normally developed first and it forms a basis from which the other plans are derived. The air movement plan is based on the ground tactical and landing plans. It specifies the schedule and provides instructions for air movement of troops, equipment, and supplies from PZs to LZs. It also provides coordinating instructions regarding air routes, air control points, and aircraft 


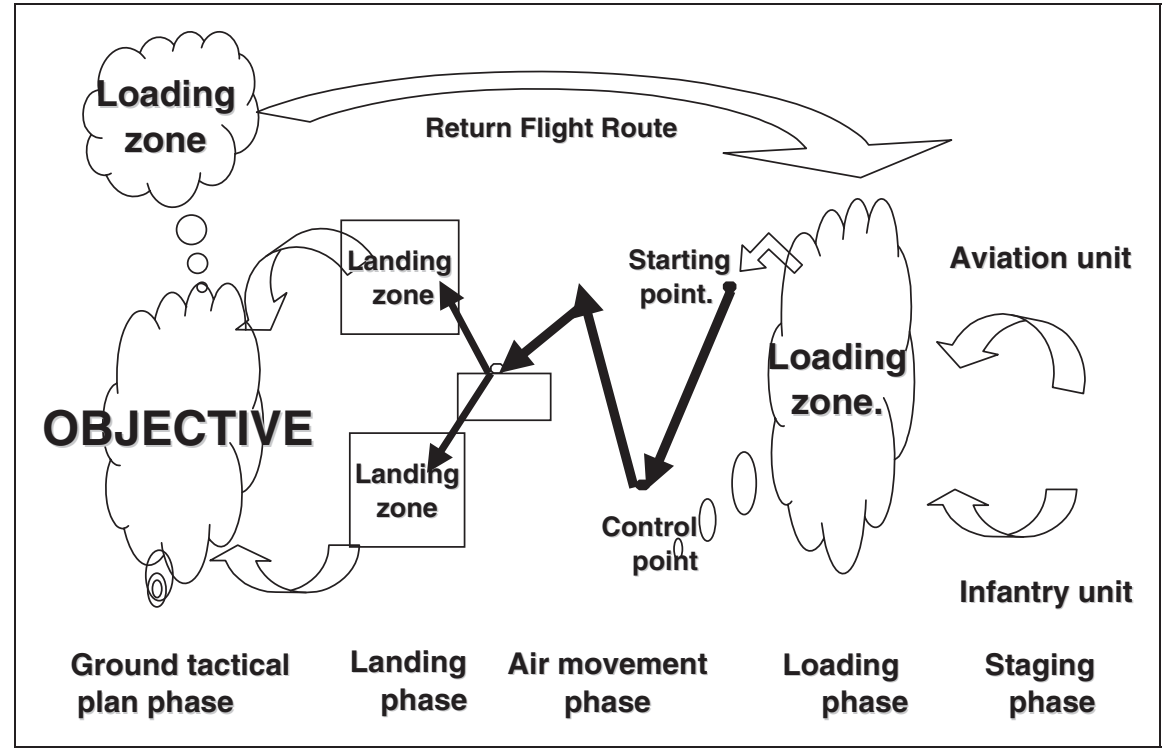

Figure I. Stages of the air assault operation.

speeds, altitudes, and formations. When operations involve multiple lifts from the same PZ, a lift table is prepared to ensure lifts are properly organized. This plan consists of aircraft allocations, number and type of each aircraft in each serial, departure point, route to and from the loading area, and loading, liftoff, and landing times. It is a basic scheduling process that the infantry units and the aviation units come together to accomplish the air movement plan. It is also very important to achieve the ground tactical plan. If it is not punctual, the commander will have some mishaps and difficulties in achieving the objective.

The loading plan is based on the air movement plan. It ensures that troops, equipment, and supplies are loaded on the correct aircraft. Unit integrity is maintained when aircraft loads are planned. However, assault forces and equipment may be cross-loaded so that command and control assets, all types of combat power, and a mix of weapons arrive at the LZ ready to fight. The loading plan should receive command attention to ensure that it goes smoothly. It is imperative for mission success that the loading operation must be well planned and properly executed.

The staging plan is based on the loading plan and prescribes the arrival time of ground units (troops, equipment, and supplies) at the PZ in the proper order for movement. Loads must be ready before aircraft arrive at the PZ; usually, ground units are expected to be in $\mathrm{PZ}$ posture 15 minutes before aircraft arrive. The staging plan also restates the $\mathrm{PZ}$ organization, defines flight routes to the PZ, and provides instructions for linkup of all aviation elements. If one can think of the air assault operations as a system, inputs of the system are the soldiers, helicopter support, and maintenance support. The main output of the system is the number of soldiers placed in the LZ.

In general, the AAOSM is developed to: (1) allow planners to build models of air assault operations early in the decision process and refine those models as their decision process evolves; (2) permit modeling of the capabilities, limitations and vulnerability of the air assault operations especially from army aviation's point of view; (3) perform 'bottleneck analysis' of the preplanned operation using statistical procedures; and (4) perform 'risk management' for operations before conducting field exercises.

By using the proposed model, commanders and the staff officers can examine the behavior of the system, establish the nature of the relationships among one or more significant factors and the system responses, and analyze the results under various scenarios. This model can also be used to select the best alternative plan according to the specific performance metrics. It can also be extended to other decision support systems by adding or subtracting the systems details under different scenarios. This research is intended to have a positive effect on the decision-making process of the staff that plan these operations and affective risk management for the decision-maker. Specifically, we determine the critical factors that affect the air assault operation and identify the scenarios under which the air assault operation is the most successful.

These issues are investigated by the simulation model which is capable of producing various statistics such as number of helicopters hit, time in maintenance, number of helicopters failed, utilization of resources, 
etc. The limitations of the model mostly come from 'the size of the system'. Owing to the difficulty of gathering quality data, the AAOSM only deals with the loading, air movement, and the landing phases of the operation and assumes that the staging phase is conducted properly beforehand. The other assumptions of our model are as follows:

- There is no escort mission by the friendly attack helicopters and there is no hindrance by the enemy attack helicopters and jetfighters during the operation.

- There are no restrictions at the PZ and LZ.

- There is no search and rescue (SAR) mission during the operation.

- The infantry units are always ready at the time of loading in the PZ.

- There are no enemy electronic countermeasures to hinder the flight of the helicopters.

- There is no friendly artillery, naval artillery, or air force support for the operation. All of the helicopters taking part in the operation are S-70 Sikorskytype utility helicopters.

- The fuel consumption is not significantly affected by the weather and terrain conditions.

These assumptions are made to keep the model details as simple as possible by focusing on the research questions only. As we explain in the validation section, these assumptions are checked by the commanders and staff. It should be noted that the proposed model is a core model. Thus, it can be a basis for future applications by relaxing one or more of the above assumptions. According to the simulation terminology, the system under consideration is the terminating system since the simulation process stops when the minimum of the below occurs:

- If all of the soldiers arrive in the LZ.

- If a total of 20 helicopters are shot by enemy.

- If a total of 20 helicopters are withdrawn from the operation due to pilot fatigue.

- If a total of 20 helicopters are out of operation due to fourth level of breakdown (that needs overall maintenance in the rear area).

The number of helicopters in the stopping conditions is dictated by the Turkish Army officials. It may correspond to the minimum size of helicopter capacity to conduct such an air assault operation. These stopping rules can be changed according to the commander's risk decisions. The input probability distributions and the variables change according to the scenarios under consideration. We explain some of the important elements of the simulation model as follows.

\section{Enemy air defense conditions}

In order to split the air movement phase of the operation we employ checkpoints in the model. These points are the places pilots use to control the time and the execution of the operation. The number of checkpoints can differ according to the terrain in the real operation. We have five different checkpoints in the flight route and five different checkpoints in the return flight route. The user can input different air defense weapons on these checkpoints according to the intelligence reports. We use typical intensity air weapons (infantry weapons, turrets, and small rockets) and input them to the fourth, fifth, LZ, sixth and seventh control points with certain probabilities. The AAOSM first checks whether there may be an enemy weapon on the control point then with certain probability it engages a weapon to the helicopter that is checking the control point. Again with certain probability the engaged weapon hits the helicopter or misses it ( $\mathrm{PH}$, probability of hit). If the weapon hits the helicopter, with another probability (PK, probability of kill) it takes the helicopter down or not. If the helicopter is downed, it is assumed that all of the soldiers are killed. If not the helicopter continues its flight. The probability distributions are taken from the database of the JANUS ${ }^{15}$ software.

\section{Weather and terrain conditions}

The proposed AAOSM operates under five different weather and terrain conditions. These are: hot weather and high terrain, hot weather and sea level, cold weather and high terrain, cold weather and sea level, night flight with night vision goggles (NVG). These conditions affect the probabilities of breakdowns occurring for helicopters and the repair times of these breakdowns. For example, in hot and high terrain conditions the breakdown and maintenance times are significantly greater than the cold and sea level conditions, but they are better than NVG conditions since it will be difficult for the maintenance personnel to repair a helicopter in night conditions during an operation.

\section{Maintenance facilities}

We have a number of maintenance stations in the AAOSM by which the helicopter technicians repair the helicopters when needed. The proposed model considers four different types of breakdown levels for the helicopters. They occur statistically within the model and the repair activities are performed according to the repair time distributions. 


\section{Refueling tankers}

The helicopters can fly for a maximum of 2 hours and 15 minutes. Then, they have to refuel in order to continue the operation. For this reason, the tankers are located in the rear operation area. Tankers are capable of refueling at most 21 helicopters. They are refilled by their own fuel depots. In the simulation model, failure or breakdown of these tankers is also considered.

\section{Pilot fatigue}

A pilot can fly for a maximum of 8 hours according to Turkish Army regulations and flight manuals. After this period they must rest for a certain period of time before flying again. In AAOSM, if a pilot exceeds 8 hours of flight limit, they are withdrawn from the operation. This feature is included in the model to identify whether pilots become a bottleneck in the system. Furthermore, due to physical stress and hardness in the environmental conditions a pilot can fly for at maximum of 4 hours in the NVG flight conditions.

We present a brief flowchart model of the system in Figure 2. The staging phase of the air assault operation is assumed to be implemented beforehand. The model performs several checks at the beginning. These checks are essential for the changes of parameters and the decision for the stopping criteria in relation to the commander's risk decisions as explained in the previous section.

According to the 'attributes and the variables' the entities encounter at those checkpoints, they are sent to the other parts of the model. The entities in the model are infantry units. The exogenous variables (input variables) are: number of helicopters, number of infantry units, number of tankers at the refueling points, capacity of tankers (number of helicopters to be served at one time), number of maintenance units, capacity of maintenance units, loading capacity of helicopters, velocity of helicopters, the distances between the PZ and the LZ, PH of the enemy air defense weapons, weather and terrain conditions. The model takes the input parameters regarding the helicopters breakdown rates, maintenance times, refueling, and pilot fatigue according to the weather and terrain conditions of a particular scenario. As helicopters complete their flight and return to their destinations, the effects of the enemy air defense weapons are evaluated. The model also checks for the accomplishment of the mission. If the mission is not yet over, the helicopters return to the LZ via the return flight route for the next sortie. The screenshot of the simulation model is given in Figure 3.

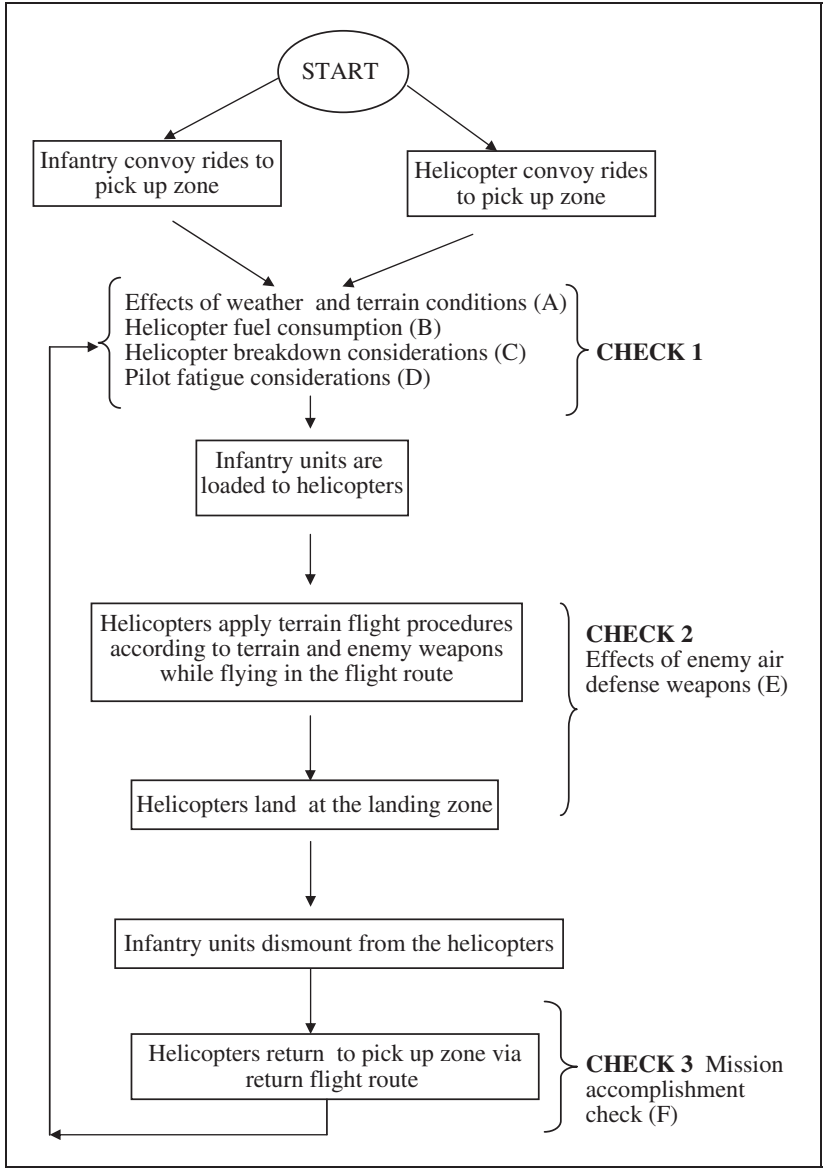

Figure 2. The flowchart of the logical model.

In the proposed system, experimental conditions of different scenarios are set easily by the using the block and animation features of ARENA (Kelton et al. ${ }^{16}$ ). The user can observe the progress of the air assault operation via both statistics and plots near the animation while running the model by using the menu buttons.

\section{I. Input data}

In this project, we have no opportunity to experience and collect data in actual war conditions. Domain experts could not suggest any distribution functions. For that reason, as recommended by $\operatorname{Smith}^{17}$ we use triangular distributions in the absence of data. The parameters of these distributions are determined by interviewing experienced pilots, technicians, and maintenance crew. Some of the data are taken from army field manuals.

Figure 3 shows an ARENA screenshot of the air assault operation written in accordance with the previous war experiences. We use these data sets to set the parameters (minimum, average, and maximum) of the triangular distributions. In future applications, the 


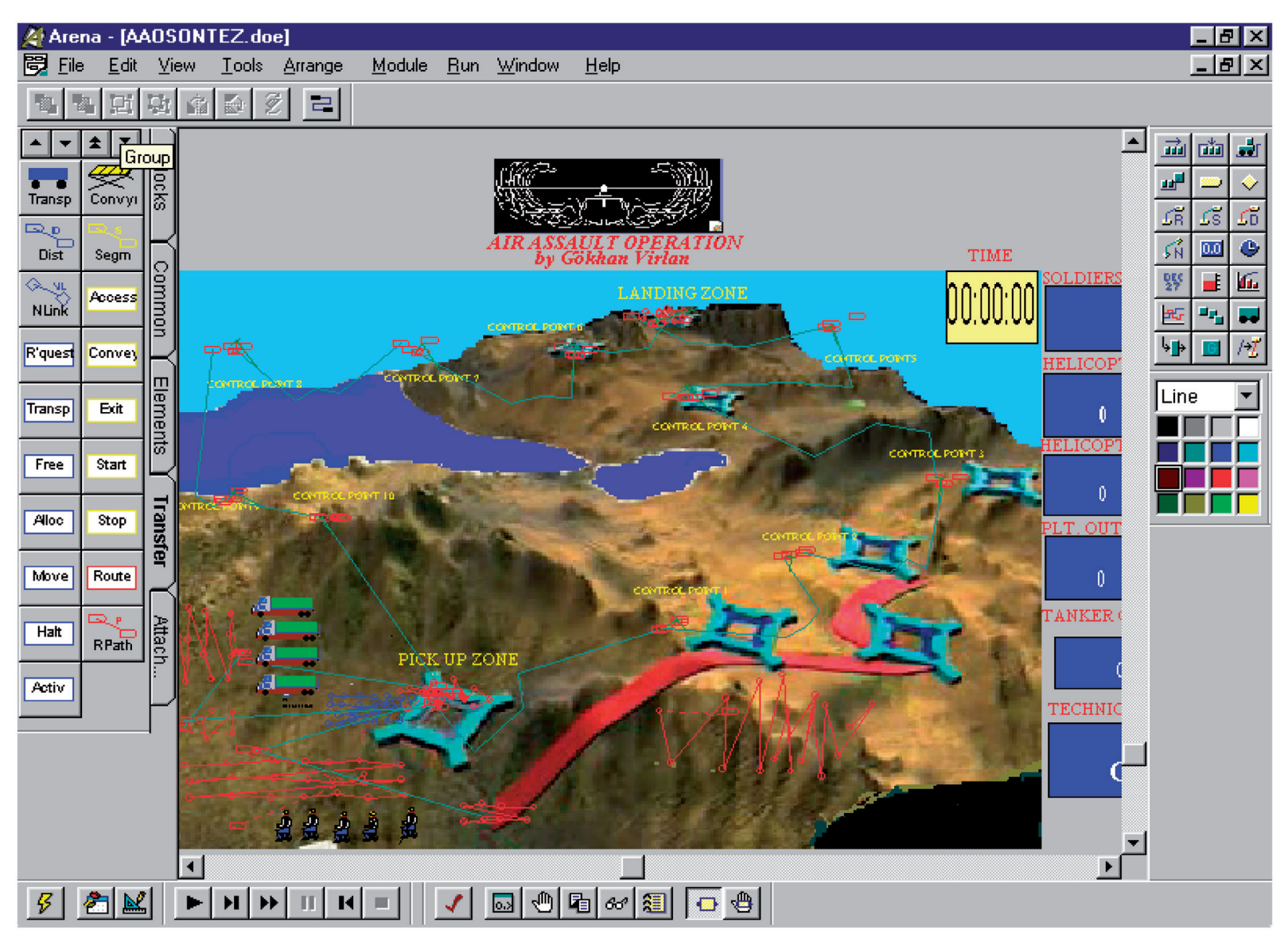

Figure 3. An ARENA screenshot of the air assault operation.

input data analysis techniques discussed in $\mathrm{Law}^{18}$ can be used to fit more suitable distribution functions.

\subsection{Validation}

It is very important to have a correct model of the system since simulation results can seriously affect the decisions of commanders. In this study, we apply several verification/validation techniques at every stage of the simulation process. End users are included throughout the process. As a face-validity, the commanders of the air assault units, the instructor pilots, and maintenance chief pilots are all employed to check the simulation results. In addition, the staff officers analyze the simulation results and observe the animation of the simulation according to their expertise. We also implement the techniques recommended by Banks $^{19}$ for verification. Specifically, we use the ARENA debugger function with the logic flow to verify whether the events occur properly in time. This also allows the simulation to be monitored as it progresses. We test our model for the different and extreme conditions to observe whether the model behaves reasonably. Since ARENA has the capability of collecting the required statistics automatically, we observe each output statistic easily. We also employ different output measures to verify other statistics (total time in system and time between some activities, queues and utilization, etc.). The computer code is also checked by the army specialists in the area of simulation.

\section{Experimental setting}

The factorial design is used to study the effects of the main factors and their joint effects on the selected performance measures. As seen in Table 1, we have five factors each with two levels. Note that the first two are quantitative factors and others are qualitative. The performance measures are: time in system, time in tanker queue, time in the maintenance queue, number of soldiers arrived to LZ, and number of helicopters that are shot during the operation. The simulation model is run for 20 replications at each 32-design point using different seeds. Bartlett's test is implemented to see whether the common variance 
Table I. Factors affecting the Air Assault Operation Simulation Model

\begin{tabular}{llll}
\hline Factor & Description & Low Level $(-\mathrm{I})$ & High Level $(+\mathrm{I})$ \\
\hline $\mathrm{I}$ & Number of tankers & 2 & 4 \\
2 & Size of the maintenance facilities & 3 & 5 \\
3 & Queue discipline for maintenance & FIFO & LVF \\
4 & Weather and terrain conditions & Cold and sea level & Hot and high \\
5 & Enemy air defense conditions & Typical & Severe \\
\hline
\end{tabular}

FIFO, first in first out; LVF, low value first.

Table 2. Summary of factor analyses

\begin{tabular}{llc}
\hline Performance Measures & Significant Factors & Magnitude of Effect \\
\hline Time-in-system & Weather and terrain conditions & $+33.48 \%$ \\
Time-in-tanker queue & Number of tankers & $-580 \%$ \\
& Weather and terrain conditions & $-27 \%$ \\
& Enemy air defense conditions & $-28 \%$ \\
& Number of tankers - weather and terrain conditions & $+16.3 \%$ \\
& Number of tankers - enemy air defense conditions & $+25 \%$ \\
Time in maintenance queue & Size of maintenance facilities & $-52 \%$ \\
& Queue discipline & $+29 \%$ \\
Number of soldiers arrived at LZ & Enemy air defense weapons & $-7 \%$ \\
& Weather and terrain conditions - & $-0.8 \%$ \\
Number of helicopters shot & enemy air defense conditions & $+51 \%$ \\
$\quad$ during the operation & Enemy air defense weapons & $-2.6 \%$ \\
\end{tabular}

LZ, landing zone.

assumption holds. The results indicate that the sample variances are equal. The validity of analysis of variance (ANOVA) assumptions is checked by examining the residuals. If the model is adequate, the residuals should be structureless; that is, they should contain no obvious patterns.

The residuals are computed by using the regression models. The scatter plots of the residuals indicate structureless patterns. The normality assumption is also checked by plotting a histogram and constructing a normal probability plot of the residuals. If this assumption is satisfied, the plot should look like a sample from a normal distribution centered at zero. The software BESTFIT (http://www.palisade.com) is used in the statistical tests. The results presented in the form of histograms and probability plots indicate that the ANOVA assumptions hold. The contrasts and $F$ statistics are also computed to determine the significance of the factors and their interactions on each performance measure. The results are summarized in Table 2. The magnitude of the effect and the direction are also supplied. The magnitude of the effect is calculated as the average performance difference between the low and high levels of that factor. A positive sign implies an increase in the value of the performance measure whereas a negative sign means a decrease in the performance measure.

\section{I. Time in system}

Time in system is an interval between the soldier arrival time at the PZ and the time they land on the LZ. As seen in Table 2 and Figure 4, which display the effect diagram, the ANOVA results indicate that the weather and terrain condition is the only significant factor. Note that when the air assault operation is conducted in the hot and high terrain condition, the time in system performance deteriorates about $33.48 \%$ as compared with the same operation conducted in the cold and sea level condition. This finding confirms that weather and terrain conditions are always important for the success of the air assault operations. The success of the ground operation phase is also related to the success of the air movement phase and punctuality 


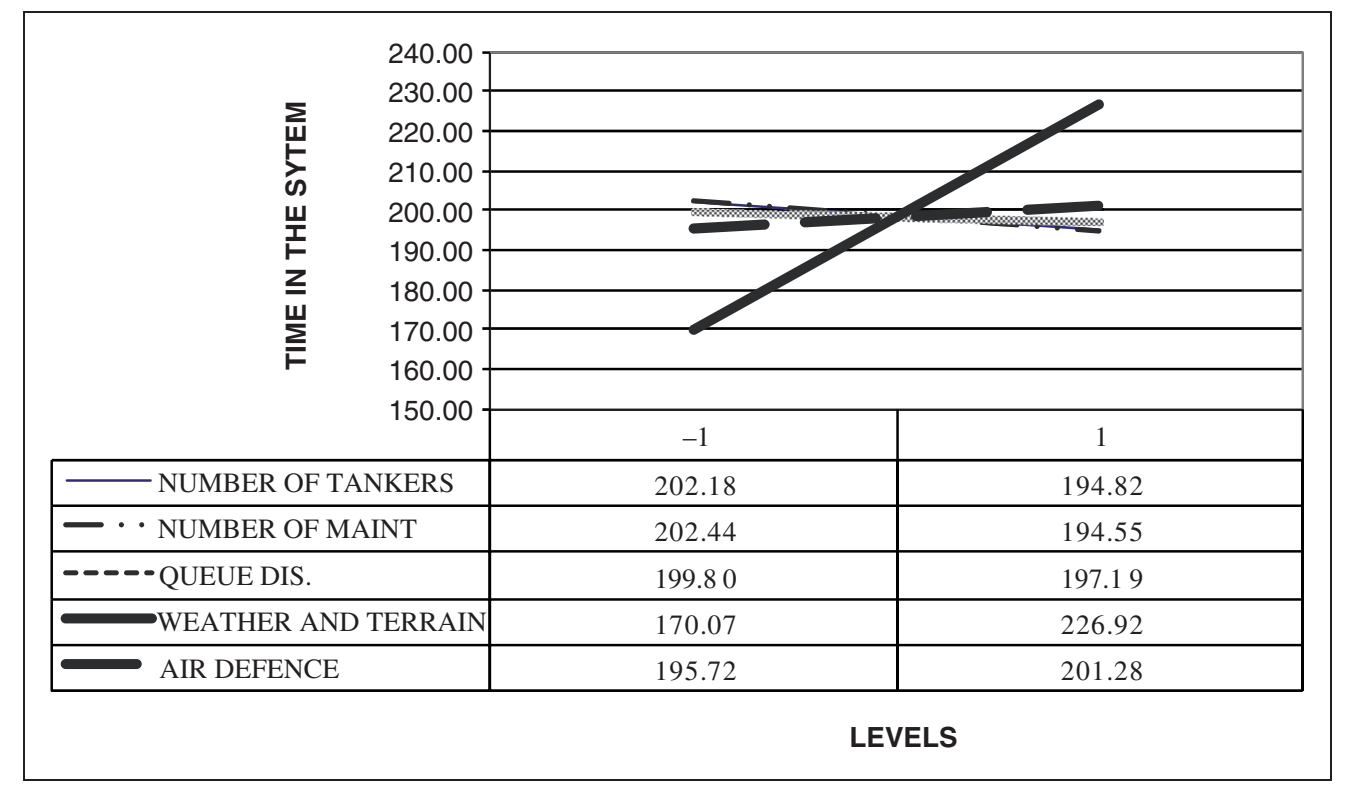

Figure 4. Effect diagram of the factors for time in system statistics.

of the troops. If the soldiers cannot arrive at $\mathrm{LZ}$ on time, they cannot support other soldiers who have previously arrived at LZ. Unfortunately, this adversely affects the success of the overall operation.

\subsection{Time in tanker queue}

According to the ANOVA results, the significant factors are number of tankers, weather and terrain conditions, and enemy air defense positions. The interaction between the number of tankers and the weather and terrain conditions, and the interaction between the number of tankers and the enemy defense positions are also significant.

As expected, allocating more tankers in the operation leads to a significant decrease in the tanker queue. This highlights the importance of the combat service support during the air assault operations. The number of the refueling tankers is also important for the utilization of the helicopters. This issue should be analyzed together with pilot tiredness considerations and helicopter maintenance policies. As explained before, a pilot cannot exceed 8 hours of daily flight limit according to Turkish Army regulations. Another significant factor is the weather and terrain conditions. The results show a $27 \%$ decrease (or improvement) in time in the tanker queue. This is due to different helicopter breakdown probabilities applied to different weather and terrain conditions. Enemy air defense positions were also found to be a significant factor. For example, when $\mathrm{PH}$ is increased by $20 \%$ from typical to severe conditions, it yields a $28 \%$ decrease in time in the tanker queue because of fewer helicopters needing to refuel due to losses.

\subsection{Time in maintenance queue}

In this case, both the capacity of maintenance facilities and the queue discipline factors are found to be significant. As expected, time in queue decreases dramatically when the size of the maintenance facilities is increased from three to five. The use of a different queue discipline also makes a significant difference yielding $29 \%$ deteriorations in the performance measure. The results suggest that if maintenance facilities are well organized in terms of the size and the use of appropriate priority rules for queues, the queue time can decrease and thus the helicopters receive the maintenance services quickly and return to their duties as early as possible. This information is especially important for the planners when very tough conditions are considered in the battlefield.

\subsection{Number of soldiers 'arrived at' $L Z$ statistics}

One of the most important statistics of the air assault operation is 'number of soldiers arrived at LZ' since this is directly related to the success of the operation. According to the ANOVA results (see Figure 5), the factor 4 (enemy air defense weapons) and the interaction of weather and enemy defense conditions (the interaction between the factor and 5) are found to be significant.

As can also be seen in Table 2, when PH data is increased by $20 \%$ to simulate the high level of the 


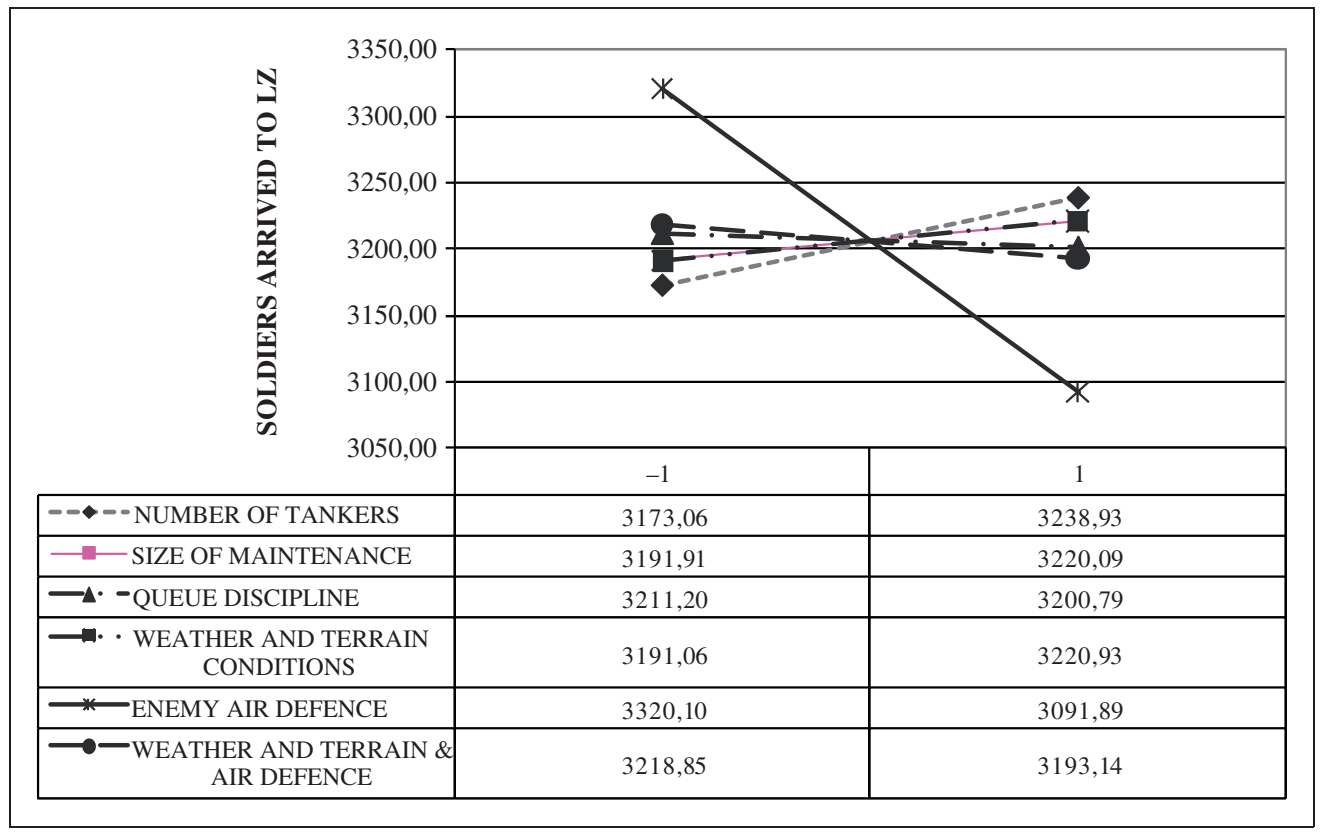

Figure 5. Main and interaction effects of the number of soldiers arriving at the landing zone statistics.

enemy air defense conditions, $7 \%$ fewer soldiers could land on the LZ. Even though this percentage seems to be small, it can still affect the troops and the ground tactical plan stage of the operation. The commanders and staff officers must take all precautions not to endanger the 'unity of the troops'.

\subsection{Number of helicopters shot}

This performance measure is directly related to the previous measure. Thus, the same factors are found to be significant. As seen in Table 2, the number of helicopters shot during an air assault operation is about $50 \%$ more in the severe enemy air defense condition than the typical condition. This clearly shows that suitable actions must be taken to reduce the number of humans lost as well as the high cost associated with S-70 type of helicopters. With this, we also understand the importance of air superiority and suppressing of air defense weapons more clearly.

\section{Analysis of alternatives}

Once the simulation model is developed, it can be used for various tasks in the analysis of the air assault operation. First, it can be used to analyze the operation and identify the important factors (critical system design parameters or operating policies). In fact, the results presented in the previous section illustrate this case. Simulation can also be used to rank the critical factors and select the best scenario for the air assault. In this section, we study these optimization issues.
In general, a commander and staff officers desire to have the optimum configuration of the forces and preserve the forces for the other parts of the combat area. In our case four factors (number of maintenance facilities, number of refueling tankers, queue disciplines, and weather and terrain conditions) are under consideration. With two levels of each factor, there are 16 factor combinations or experimental conditions (see Table 3). In the simulation experiments, we use three and five as the values of the maintenance facilities, and two and four for the number of tankers according to the army aviation regiment for an air assault operation. Moreover, we use two enemy air defense conditions and two different weather and terrain conditions (hot and high, cold and sea level). For a queue discipline of the maintenance facilities, we use the first in first out (FIFO) and low value first (LVF) rules. Here, the objective of the simulation study is to select the best factor combination or scenario (called system or system design) for the selected performance measures. The model is run for 28 helicopters (air assault helicopter battalion) and 1 commando brigade. In the simulation runs, the flight route takes about 40 minutes.

We employ ranking and selection (R\&S) and multiple comparison procedures (MCPs) to analyze the simulation results. These two techniques are suitable for simulation optimization when the input parameters are discrete and the number of designs to be compared is both discrete and small (i.e. 2 to 20). In general, MCP is used to differentiate alternatives so as to screen out inferior alternatives before selecting the best system 
Table 3. Scenarios of the Air Assault Operation Simulation Model

\begin{tabular}{|c|c|c|c|c|}
\hline $\begin{array}{l}\text { Scenario } \\
\text { Number }\end{array}$ & $\begin{array}{l}\text { Weather and } \\
\text { Terrain } \\
\text { Conditions }\end{array}$ & $\begin{array}{l}\text { Number of } \\
\text { Maintenance } \\
\text { Facilities }\end{array}$ & $\begin{array}{l}\text { Number } \\
\text { of Tankers }\end{array}$ & $\begin{array}{l}\text { Queue } \\
\text { Discipline in } \\
\text { Maintenance } \\
\text { Facilities }\end{array}$ \\
\hline I & Hot and High & 5 & 4 & FIFO \\
\hline 2 & Hot and High & 5 & 4 & LVF \\
\hline 3 & Hot and High & 5 & 2 & FIFO \\
\hline 4 & Hot and High & 5 & 2 & LVF \\
\hline 5 & Hot and High & 3 & 4 & FIFO \\
\hline 6 & Hot and High & 3 & 4 & LVF \\
\hline 7 & Hot and High & 3 & 2 & FIFO \\
\hline 8 & Hot and High & 3 & 2 & LVF \\
\hline 9 & $\begin{array}{l}\text { Cold and Sea } \\
\text { Level }\end{array}$ & 5 & 4 & FIFO \\
\hline 10 & $\begin{array}{l}\text { Cold and Sea } \\
\text { Level }\end{array}$ & 5 & 4 & LVF \\
\hline II & $\begin{array}{l}\text { Cold and Sea } \\
\text { Level }\end{array}$ & 5 & 2 & FIFO \\
\hline 12 & $\begin{array}{l}\text { Cold and Sea } \\
\text { Level }\end{array}$ & 5 & 2 & LVF \\
\hline 13 & $\begin{array}{l}\text { Cold and Sea } \\
\text { Level }\end{array}$ & 3 & 4 & FIFO \\
\hline 14 & $\begin{array}{l}\text { Cold and Sea } \\
\text { Level }\end{array}$ & 3 & 4 & LVF \\
\hline 15 & $\begin{array}{l}\text { Cold and Sea } \\
\text { Level }\end{array}$ & 3 & 2 & FIFO \\
\hline 16 & $\begin{array}{l}\text { Cold and Sea } \\
\text { Level }\end{array}$ & 3 & 2 & LVF \\
\hline
\end{tabular}

FIFO, first in first out; LVF, low value first.

design. R\&S is used to select the best system design. Generally speaking, selecting the best system helps the commander and the staff officers to know which scenario is the most suitable in conducting the air assault operations. The performance measures under consideration are: time in system, time in tanker queue, time in maintenance queue, and number of soldiers arrived at LZ. Since the number of helicopters shot during the air assault operation has similar behavior to the number of soldiers arrived at LZ, it is omitted from the rest of the study.

\section{I. Comparison of the scenarios with MCPs}

As stated before, MCPs are suitable for comparing different alternatives. In our case, the commander would know which configuration of their force is inferior with respect to the performance metric under consideration. This information may be vital in a battlefield situation.
Table 4. The results of the Tukey test

\begin{tabular}{|c|c|c|c|c|}
\hline $\begin{array}{l}\text { Weather and } \\
\text { Terrain } \\
\text { Conditions }\end{array}$ & $\begin{array}{l}\text { Time in } \\
\text { System }\end{array}$ & $\begin{array}{l}\text { Time in } \\
\text { Maintenance } \\
\text { Queue }\end{array}$ & $\begin{array}{l}\text { Time in } \\
\text { Tanker } \\
\text { Queue }\end{array}$ & $\begin{array}{l}\text { Number of } \\
\text { Soldiers } \\
\text { Arrived } \\
\text { at LZ }\end{array}$ \\
\hline $\begin{array}{l}\text { Cold and } \\
\text { Sea Level }\end{array}$ & - & 16 & $11,12,15,16$ & - \\
\hline Hot and High & - & $5,7,8$ & 4,8 & 8 \\
\hline
\end{tabular}

LZ, landing zone.

There are a number of multiple comparison procedures in the literature. With any one of these procedures, the observed difference between two alternatives (usually mean performances) is compared with the appropriate critical value. If the observed difference exceeds this predetermined critical value, the two means are declared significantly different; otherwise, the difference is considered non-significant. We employ the Tukey test (Montgomery ${ }^{20}$ ) and the Welch approach in our study. The results of the Tukey test are given in Table 4. The numbers in the cells corresponds to the scenarios that should be eliminated from further considerations. For example, in the cold and sea level condition, none of the alternatives are differentiated from each other for the time in system measure. However, Scenario 16 is found to be inferior for the time in maintenance queue performance measure since its mean value is significantly higher than the means of other conditions.

We also use the Welch approach to gain better insights about the competitive alternatives. At this stage, instead of having all pairwise comparisons among the alternatives, we compare the two most competitive alternatives. As seen in Table 5, the Welch approach differentiates more alternatives than the Tukey test. For example, Scenarios 12, 13, 14, 15, 16 are found to be inferior in the cold and sea level weather and terrain conditions, and therefore they are eliminated from further considerations.

\subsection{Selecting the best system}

In most simulation studies, the goal is to select the best system from a set of alternatives for a given performance measure. In our case, it is desired to select the system with the smallest expected average time in system, time in the maintenance queue, and time in tanker queue; and the largest average number of soldiers arrived at landing zone under different weather and terrain conditions.

We use the Dudewicz-Dalal $\left(\operatorname{Law}^{18}\right)$ procedure to select the best from $k$ alternative systems. This procedure involves 'two-stage' sampling. In the first stage, 
Table 5. The results of the Welch approach

\begin{tabular}{lllll}
\hline Weather and & Time in & & & Number of \\
Terrain Conditions & the System & $\begin{array}{l}\text { Time in the } \\
\text { Maintenance Queue }\end{array}$ & $\begin{array}{l}\text { Time in the } \\
\text { Tanker Queue }\end{array}$ & $\begin{array}{l}\text { Soldiers } \\
\text { Arrived to LZ }\end{array}$ \\
\hline Cold and Sea Level & II & $12,13,14,15,16$ & $11,12,15,16$ & - \\
Hot and High & $3,5,7,8$ & $4,5,6,7,8$ & $3,4,7,8$ & 3,5 \\
\hline
\end{tabular}

$\mathrm{LZ}$, landing zone.

Table 6. The best systems for the performance measures

\begin{tabular}{lllll}
\hline $\begin{array}{l}\text { Weather and } \\
\text { Terrain Conditions }\end{array}$ & $\begin{array}{l}\text { Time in } \\
\text { the System }\end{array}$ & $\begin{array}{l}\text { Time in the } \\
\text { Maintenance Queue }\end{array}$ & $\begin{array}{l}\text { Time in the } \\
\text { Tanker Queue }\end{array}$ & $\begin{array}{l}\text { Sumber of } \\
\text { Ardiers } \\
\text { Arived at LZ }\end{array}$ \\
\hline Cold and Sea Level & 10 & 10 & 13 & 10 \\
Hot and High & 4 & 3 & 1 & 2 \\
\hline
\end{tabular}

LZ, landing zone.

for a fixed number replications (i.e. $n_{\mathrm{o}}=20$ ) we compute the mean and variance estimators for each alternative system. At the second stage, using these variance estimates from the previous stage we calculate the total number of simulation runs required to find the best system.

Generally speaking, due to the inherent randomness of the observations taken from the simulation model, nobody can ever be absolutely sure that the selected system is actually the best system. Hence, we have to define the probability of correct selection. In the standard applications of the Dudewicz-Dalal procedure, this probability is set to $90 \%(p=0.90)$. Furthermore, alternatives are sometimes so close to each other that the correct selection might require an enormous number of simulation runs. To prevent this, the indifference amount $d$ is defined so that the decision maker does not care whether the second best alternative is erroneously selected as long as the difference is no more than $d$. This avoids a large number of simulations runs to resolve unimportant differences. In our case, we take 20 initial independent replications from each system and determine the desired probability of correct selection. The indifference amount between the mean response of the first ranked system $m_{[2]}$ and the mean response for the second ranked system $m_{[1]}$ as $h(0,9,8,20)=3.051\left(\mathrm{Law}^{18}\right)$. The $d$ values for the alternatives are:

- time in the system $d=15$ minutes;

- time in the maintenance queue $d=60$ minutes;

- time in the tanker queue $d=5$ minutes;

- number of the soldiers landed $d=180$ soldiers (two teams).
These values represent the commander's risk decisions for a particular weather and terrain condition. If the differences between the scenarios are less than these values, the selected system is treated as good as the best system. If a commander wants to be strict on the differences, the results may change. We chose these values such that they can alter the outcome of the operation. The results are presented in Table 6 .

Note that the best system differs for each performance measure as well as the weather and terrain conditions under consideration. In the cold and sea level condition, Scenario 10 is the best system for most of the performance measures. This information can be important for the commander to develop suitable tactics for the air assault operations. For example, if the enemy air assault weapons and jet fighters are superior to the friendly weapons, the commander may decide to minimize the time in the system of the soldiers and select Scenario 4. Furthermore, if the operation seems to fail due to the long maintenance times of the helicopters, they might select Scenario 3. Thus, this approach gives valuable insight to the commander and his staff.

\subsection{Selecting a subset of size $\boldsymbol{m}$ containing the best of $\mathbf{k}$ systems}

The commander and staff officers may desire to screen out some alternatives and make a decision quicker without analyzing the inferior ones. This process saves time and assists the decision maker in time management of the headquarters' activities.

Selecting a subset of size $m$ of the $k$ systems could tbe a useful goal in the initial stages of any 
Table 7. The subset of four containing the best of 16 systems for the performance measures

\begin{tabular}{lllll}
\hline $\begin{array}{l}\text { Weather and } \\
\text { Terrain Conditions }\end{array}$ & $\begin{array}{l}\text { Time in } \\
\text { the System }\end{array}$ & $\begin{array}{l}\text { Time in the } \\
\text { Maintenance Queue }\end{array}$ & $\begin{array}{l}\text { Time in the } \\
\text { Tanker Queue }\end{array}$ & $\begin{array}{l}\text { Number of } \\
\text { Soldiers } \\
\text { Arrived at LZ }\end{array}$ \\
\hline Cold and Sea Level & $9,10,14,16$ & $10,12,13,16$ & $9,10,13,14$ & $10,12,13,16$ \\
Hot and High & $2,4,5,8$ & $1,2,3,5$ & $1,2,5,6$ & $1,2,7,8$ \\
\hline
\end{tabular}

LZ, landing zone.

simulation study. Because there may be a large number of alternatives, an initial screening is needed to eliminate those that appear to be clearly inferior. This also avoids expending a large amount of computer time in obtaining precise estimates of the behavior of these inferior systems. Table 7 summarizes our findings for different weather and terrain conditions.

This procedure does not select the best scenario but rather identify a subset that contains the best. For example, for the hot and high terrain conditions for the time in system measure, the set consisting of Scenarios 2, 4, 5, and 8 contains the best alternative. This approach might be useful in the battlefield particularly when there is not much time analysis. Thus, the commander can concentrate on these alternatives without even considering the others. It will also save the commander's staff time on the battlefield.

\section{Conclusion}

In this study, we have developed a simulation model to analyze the behavior of air assault operations on a typical battlefield for different performance measures. The results of the simulation experiments indicate that weather and terrain conditions and enemy air defense capabilities appear to be the most significant factors for all performance measures. Air assault operations are very vulnerable to both of these factors. The ground tactical phase of the operation is strongly related to the changing conditions in both factors. The planners must be aware of the fact that these two factors can alter the outcome of an operation and may even lead to failure. The commanders and the staff officers must take precautions to suppress enemy air defense capabilities. The equipment in the helicopters and the training of the pilots must be adequate to fly in all weather conditions. The breakdown ratio of the helicopters and the refueling tankers must be reduced by using proper equipment and better training. Queue discipline in the maintenance queue is also the significant factor. This implies that the maintenance facilities can be configured to use different queue disciplines.

We also applied the R\&S procedures to select the best scenario for particular weather and terrain conditions and conserve both manpower and equipment for use in other areas of the battlefield. We observe that the best system differs for different performance measures. This suggests that the commander must analyze changing conditions in the operation and select the best scenario according to the performance measure most critical for the success of the operation. The subset selection procedure is also used to save time by screening out the inferior alternatives and giving planners other alternatives when the best system is impossible to implement.

Air assault operations are usually very important for the military. In this study, we do not include the staging and ground tactical operation phase of air assault operations due to time and data limitations. This can be undertaken in future studies. Moreover, the model can be extended to analyze air assault plans by some minor modifications and using real data. Some further developments on the plans can also be made and tested in the proposed simulated environment.

\section{Funding}

This research received no specific grant from any funding agency in the public, commercial, or not-for-profit sectors.

\section{Conflict of interest statement}

None declared

\section{References}

1. Henry $H$. The corps battle simulation: remodeling the model for new missions. In: Proceedings of the 1994 Winter Simulation Conference, 1994, pp. 788-791.

2. Blais CL. Marine air ground task force (MAGTF) tactical warfare simulation (MTWS). In: Proceedings of the 1994 Winter Simulation Conference, 1994, pp. 839-844.

3. Garrabbrants WM. Simulation as a mission planning and rehearsal tool. In: Proceedings of the 1998 Winter Simulation Conference, 1998, pp. 849-853.

4. Rubin PE and Sowers JL. Air operations modeling in a wargaming environment. In: Proceedings of the 1988 Winter Simulation Conference, 1988, pp. 736-743.

5. Litko JR and Carter WB. A desert storm crew flying hour model. In: Proceedings of the 1991 Winter Simulation Conference, 1991, pp. 535-541. 
6. Zahn EA, Stute NJ and Clark PK. An object oriented simulation of air force support equipment usage. In: Proceedings of the 1995 Winter Simulation Conference, 1995, pp. 1193-1199.

7. Briggs DD, Mollaghasemi $M$ and Sepulveda JA. A hybrid analytical/simulation modeling approach for planning mass tactical airborne operations. In: Proceedings of the 1995 Winter Simulation Conference, 1995, pp.1257-1261.

8. Fossett CA, Harrison D, Weintrob H and Gass SI. An assessment procedure for simulation models: a case study. Operations Research 1991; 39: 710-723.

9. Popken D and Cox L. A simulation optimization approach to warfare planning. The Journal of Defense Modeling and Simulation 2004; 1: 27-140.

10. Taylor B and Lane A. Development of a novel family of military campaign simulation models. Journal of the Operational Research Society 2004; 55: 333-339.

11. Rosenthal RE and Walsh WJ. Optimizing flight operations for an aircraft carrier in transit. Operations Research 1996; 44: 305-312.

12. Baker SF, Morton DP, Rosenthal RE and Williams LM. Optimizing military airlift. Operations Research 2002; 50: 582-602.

13. Schumacher C, Chandler PR, Pachter M and Pachter LS. Optimization of air vehicle operations using mixed integer programming. Journal of the Operational Research Society 2007; 58: 516-527.

14. Turner DD and Carstens CB. Future force warrior: insights from air assault expeditionary force assessment. US Army Research Laboratory, July 2007.

15. JANUS Software. http://www.leav.army.mil-/nsc/ famsim/janus/index.htm.

16. Kelton WD, Sadowski RP and Swets NB. Simulation with ARENA, 5th ed. New York: McGraw-Hill, 2010.

17. Smith RD. Essential techniques for military modeling and simulation. In: Proceedings of the 1998 Winter Simulation Conference, 1998, pp. 805-812.

18. Law AM. Simulation Modeling and Analysis, 4th ed. New York: McGraw-Hill, 2007.

19. Banks J. Handbook of simulation, John Wiley \& Sons, Inc., 1998.
20. Montgomery DC. Design and Analysis of Experiments, 4th ed. New York: John Wiley \& Sons Inc, 1992.

Ihsan Sabuncuoglu is Professor and Chair of Industrial Engineering at Bilkent University. He received the BS and MS degrees in Industrial Engineering from Middle East Technical University and the $\mathrm{PhD}$ degree in Industrial Engineering from the Wichita State University. He teaches and conducts research in the areas of simulation, scheduling, and manufacturing systems. He has published papers in, IIE Transactions, Decision Sciences, Simulation, International Journal of Production Research, International Journal of Flexible Manufacturing Systems, International Journal of Computer Integrated Manufacturing, Military Operations Research, Computers and Operations Research, European Journal of Operational Research, International Journal of Production Economics, Production Planning, Control, Journal of the Operational Research Society, Journal of Intelligent Manufacturing, and Computers and Industrial Engineering. $\mathrm{He}$ is on the Editorial Board of International Journal of Operations and Quantitative Management, International Journal of Systems Sciences, Journal of Operations Management, and International Journal of Computer Integrated Manufacturing. $\mathrm{He}$ is an associate member of the Institute of Industrial Engineering and Institute for Operations Research and the Management Sciences.

Gökhan Virlan received his BS degree in Electrical and Electronics Engineering from Army War Academy in 1993. He worked as an army pilot in various fleets of the Army. In 2001, he received his MS degree in Industrial Engineering from Bilkent University. He is a rotary wing flight instructor and Simulator department section chief at the Army Aviation School. His research includes military simulation, risk management in aviation, and re-engineering of the real models. 